\title{
SEPARATING THE RELEVANT FROM THE IRRELEVANT: THE SRI LEARNING MODEL
}

\author{
Nenad Suzić ${ }^{1}$, Vera Jelić ${ }^{2}$, and Ankica Milivojac ${ }^{3}$ \\ ${ }^{1}$ Faculty of Philosophy, University of Banja Luka, Bosnia and Herzegovina \\ ${ }^{2}$ Elementary school "Petar Kočić" Šibovska, Prnjavor, Bosnia and Herzegovina \\ ${ }^{3}$ Pedagogue, unemployed, Bosnia and Herzegovina
}

EDITORIAL ARTICLE

ORIGINAL SCIENTIFIC PAPER

doi: 10.5550/sgia.130902.en.001S

UDC: $378.014 .3: 371.147$

\begin{abstract}
SUMMARY
The present study shows an experimental application of the SRI model of studying in teaching. We are talking about separating the relevant from the irrelevant, i.e. the SRI model which was applied in a group rotation experiment. Namely, the first group, which included the second, the third and the fourth class, applied the mentioned model for twelve lessons, and three parallel classes represented group K, which applied traditional teaching models. After the twelve lessons the effects of the SRI model in group $\mathrm{E}$ and traditional teaching in group $\mathrm{K}$ were measured. Then, the students from group $\mathrm{K}$ applied the SRI model for twelve lessons, and group E applied traditional teaching models. Again, with the completion of both, measurements were conducted once again. The measurement included students' motivation, the way they evaluated the material and how many important facts they memorized from the material. The results show that the application of the SRI model gives better effects when it comes to motivation, evaluation of the material and memorizing facts.
\end{abstract}

Key Words: material evaluation, memorizing facts, motivation, studying, students' activity.

\section{INTRODUCTION}

Phrase separating the relevant from the irrelevant requires a selective approach, which implies that the individual is focused on limited aspects of what is being observed (Myers, 1989), selective memory, related to the expectations of the individual during the process of memorizing (Bugg \& McDaniel, 2012; Gilovich, Griffin, \& Kahneman, 2002), and selective metacognition, which implies the individual's ability to choose information which he will cognitively abstract (Ibid). If we want to analyze all the aspects of separating the relevant from the irrelevant in one theoretical framework then we have to turn to the theory of selective learning (Bandura, 1969, 1977; Restle, 1957). Separating the relevant from the irrelevant is an individual, but a social act as well. Albert Banduna calls this social aspect selective activation, and this means that the individual selectively directs his activity towards social setting. This thesis Bandura elaborates in the theory of selective learning (1969).
At times of learning civilization, at times of fast information production, it is not possible to retain memory reproductive concept of school teaching and education typical for the $19^{\text {th }}$ and the $20^{\text {th }}$ centuries. In order not to learn everything that is in the curriculum and syllabus and textbooks, the student needs to learn how to separate the relevant from the irrelevant. In order to achieve this, we need to train students to ask questions and give answers (Bugg \& McDaniel, 2012), to read selectively and actively (McNamara, 2004), to understand the things they are learning (Noordman, Vomk, \& Kempff, 1992), to evaluate their own activity (Rogers, 1969). All this can only be accomplished with the teacher's ability to engage or interactively include students into the process.

People read at four levels: (1) by recognizing graphemes, graphic signs for phonemes, (2) distinguishing concepts, i.e. words or groups of phonemes separated from other words, then (3) understanding sentences which represent graphical signs for thoughts and (4) understanding ideas which are graphically 
presented in passages, i.e. in several sentences centered around the main sentence, like bees around the queen. Schools train students to read at the third level, and the fourth level is a precondition for efficient and fast reading (Fry, 1996) and is something which is unattainable in schools today. How to understand ideas and separate the relevant? First, view the text vertically. Second, recognize the key facts. Third, ask the key question for each idea. Fourth, circle the key information or thoughts (Ibid, p. 61). This simple method can be applied in the existing curriculums and syllabuses and textbooks. It is precisely this that we researched in the three school subjects of lower-class teaching.

According to researches, if the student asks questions on his own about the topic being learned and answers them or if we form groups which will answer these questions, this will significantly improve metacognitive understanding and memorizing the material (Griffin, Wiley, \& Thiede, 2008; Thiede, Anderson, \& Therriault, 2003; Thiede, Griffin, Wiley, \& Anderson, 2010). If the teacher applies methods which will direct the students to separate the relevant from the irrelevant, to ask and answer questions on their own, this will lead to accurate metaobservation of what is being learned (Bugg \& McDaniel, 2012). This research shows that groups which asked and answered questions on their won were more successful at memorizing what was being learned (Ibid, p. 927).

Researches (TIMMS, PISA) also show that economically most prosperous countries are not necessarily best at classical school proficiency tests (Zhao, 2009). The reason for this is that in the traditional teaching practice students have to learn a lot of the material in the curriculum and syllabus which is contained in textbooks. It is necessary to train students how to value the material, to identify what is important and not to learn everything. Researches also show that emotions and moral judgment about the material significantly influence students' motivation (Ugazio, Lamm, \& Singer, 2012). While testing the preconceptions of students about whether their actions will have a negative or neutral outcome, the results show that preconceptions affect motivation but are unreliable (Young, Camprodon, Hauser, Pascual-Leone, \& Saxe, 2010). It is precisely this dimension of evaluating the material that this research is concerned with. Namely, we conducted an experiment in order to find out if students who think that the material they are learning is important are better at learning and memorizing than students who have an indifferent attitude towards the same material.
Students who take notes and learn from them, in general learn more (Kiewra et al., 1991), and when they note down the key and the most important ideas, learning improves and is raised to the next level (Huffman \& Spires, 1994). This efficiency is more emphasized if students analyze and value the things marked as relevant, if they evaluate ideas (Mayer, 2002; Rinehart \& Thomas, 1993). Our experimental research comprises all three levels of separating the relevant from the irrelevant. Specifically, we measured their curiosity, imagination, challenge, affirmation and knowledge change if they learn based on the SRI model in relation to the traditional way of learning.

When students themselves ask and answer questions in a group interaction they memorize information better than the groups which read the text again or just repeat the information (Bugg \& McDaniel, 2012). In our SRI experiment we applied a group interaction which meant that the students asked key questions and answered them as a group. We immediately noted noticeable effects, but after a several workshops the results were clearly visible. For metacomprehension of the material a certain amount of time must pass in the application of separating the relevant from the irrelevant (Son \& Metcalfe, 2000. It is completely understandable that students need time to master the SRI model. It is for this reason that we tested the influence of time on curiosity, imagination, challenge, affirmation and the knowledge of students.

In order to improve efficient memorizing of the material, it is necessary to secure active participation of students in teaching. Some researches show that the techniques teachers employ to secure active participation of their students in conceptual mapping and self-explanation of the material significantly improves metacomprehension of the material (Thiede et al., 2003; Thiede et al., 2010). Traditional teaching in its predominantly teaching and didactical paradigm renders the student a receptive passive listener which needs only to memorize and repeat what the teacher and textbooks say. This didactical approach rendered the student a passive listener, and rarely enabled an active participation in teaching. Active participation of the student in our research was conducted by applying group work, presentations and evaluation of students.

The starting hypothesis of the research is that the SRI learning model gives better results in regard to evaluating the material, memorizing facts, and motivational components such as curiosity, imagination, challenge, affirmation and competence in relation to the traditional way of teaching. 


\section{METHODS}

\section{Sample}

The sample included 85 students from the elementary school "Petar Kočić" in Šibovsko, a village near Prnjavor, a town near Banja Luka $(\mathrm{BiH})$. There were 45 girls and 40 boys $\left(\chi^{2}=29\right.$, is not statistically important), which means that the sample was gender uniform. Mean age was from 7 to 10 years old.

\section{Design and procedure}

The research was conducted experimentally with the rotation of $\mathrm{E}$ and $\mathrm{K}$ groups. The experimental SRI program was tested on three school subjects, Math (fourth class), L1 (third class) and Nature and Society (second class). In the three E group classes the teaching process was performed based on the SRI model, and in the parallel three $\mathrm{K}$ group classes the teaching process was realized based on the traditional concepts. Then the experimental SRI program was tested in group $\mathrm{K}$ making them an experimental group, and group $\mathrm{E}$ was subjected to the traditional teaching. With $\mathrm{E}$ and $\mathrm{K}$ group rotation we excluded any possibility of the effect of the SRI program being associated to individual characteristics of students of one or the other group, we eliminated subjective influence of the teachers since the same teachers participated in the $\mathrm{E}$ and $\mathrm{K}$ teaching design.

At the beginning of the research the students had to fill in two instruments: SMMSC test (Suzić, 2008) and TM profile (Jelić, 2013). During the implementation of the SRI program the students were instructed how the read the paragraphs and based on each paragraph ask one question and write a key thesis. Based on these theses the students prepared presentations with the help of textbooks and the teacher, after which the presentations were evaluated by the other groups. After the presentations the teacher and the students analyzed the key questions and the key information learned in the material. After the realization of the SRI experimental program proficiency tests were conducted from three subjects in all six classes. The same tests were used in both $\mathrm{E}$ and $\mathrm{K}$ groups. In the proficiency test the students were asked to fill in the SMMSC tests again and TM profile. The experimental SRI program was thus conducted in $\mathrm{K}$ groups, while E groups were control groups. After this the students did proficiency tests and the SMMSC test and the TM profile. Repeated testing helped us to measure the influence of time as a variable important for the experimental program. All the students and the teachers participated in the experiment vo- luntarily, and after the experiment many asked if the program was going to be continuously applied or if they could it carry it out without the examiners. We regarded these questions as support and, of course, we approved the application of the SRI model in the teaching process.

The SRI program is designed so it gradually by steps trains students to ask questions or write a shorter thesis, sometimes even a single word for every paragraph in the book, for every idea presented by the teacher. After each student has written a question, small groups are formed so the first group can prepare a presentation which can answer the first few questions, the second group can answer the following questions and so on. The presentation is followed by evaluation of the quality of presentation, and together with the teacher evaluation of the key facts and information. Thus the students are gradually prepared to separate the relevant from the irrelevant.

\section{Instruments}

We will describe the instruments in detail so it is clearer how the effects of the experimental SRI program were measured.

SMMSC test: Students' Motivation to Memorize Senseless Contents (Suzić, 2008) has 25 items divided into five subtests: curiosity, imagination, challenge, affirmation and competence. The data on inner consistency are compatible with former calibration (2008) where Cronbach's alpha was $\dot{\alpha}=.73$, and in this research is $\dot{\alpha}=.84$, which is a respectable level of consistency. The logics for the application of this instrument is the fact that it represents an excellent general indicator of motivation, and we needed an instrument which is neutral in measuring motivation regardless of the school subject, i.e. the content of learning. This instrument implied that the examiner read statements, and the examinees circled one of the four numbers on the scale from $1=$ completely false for me to $4=$ entirely true for me. For example, one statement said: I love mysteries - related to imagination, and the other said: I love complicated situations and complex tasks - related to challenge.

TM profile: The Importance of the Teaching Material (Jelić, 2013) is an instrument designed for this research, it contains 11 situations where students have to choose one of the three forced-choice answers related to the material: important, interesting and non-selective. For example, the situation is following: While the teacher is presenting a new material, you 1) want to memorize everything, but cannot achieve it (non-selective), b) want to memorize what is interesting (interesting) and c) are trying to memorize the 
most important (important). After 11 such choices this instrument represents an excellent selection for three value orientations. The same results can be found in Kendall tau rank correlation coefficients which perfectly depict orthogonality between variables (Bryman \& Cramer, 2001, p. 179). The correlation between important and interesting is $r=-.10$, between interesting and selective non-selective is $r=-.23$, and between non-selective and important is $r=-.79$. These coefficients undoubtedly confirm that there is orthogonality between three value orientations measured by the TM profile.

Proficiency tests are calibrated with Cronbach's alpha coefficient for inner consistency. There are total of six tests. The first test is IT-L1: L1 initial test $(\dot{\alpha}=.79)$, the second is FT-L1: final L1 test $(\dot{\alpha}=.79)$, the third is IT-N: initial Nature test $(\dot{\alpha}=.67)$, the fourth is FT-N: final Nature test ( $\dot{\alpha}=.68)$, the fifth is IT-M: initial Math test $(\dot{\alpha}=.75)$ and the sixth is FT-M: final Math test $(\dot{\alpha}=.77)$. These are short tests which contain only important information from the textbooks. All coefficients are high enough in order for us to validly judge the level of adoption of the key information. The validity of comparison lies in the fact that both $\mathrm{E}$ and $\mathrm{K}$ groups used the same tests.

\section{Conceptual questions}

The first question concerned how the students would react to the idea that the SRI implies working independently. At first, there was a slight hesitation and distance, but by the third lesson they "swallowed the bite" and it was easy to see that they enjoyed this approach. When we measured the effects of facts adoption we expected this to be less efficient than in the traditional approach which the students were accustomed to, but it turned out that the SRI model was more efficient here. In terms of emotions we did not measure the SRI effects, but the instrument SMMSC test significantly indicated student's emotionality ("I am happy...", "I love when..." and alike), so we judged about emotions indirectly, but it would have been better if we had tested them directly. This is also one of the weaknesses of this research, so we suggest that researchers take this fact into account in further experiments, especially since there are excellent instruments for measuring emotions and students' emotionality.

The second conceptual question is how to direct traditional teaching from reproductive memory conception to learning how to learn, to the development of managerial and interactional competencies. We are convinced that the SRI model contributes to this, especially since it is compatible with traditional teaching methods and patterns.

In this research we anticipated that the SRI learning model would contribute to better memorizing of the material, that it would strengthen motivational components of learning and motivate students to strengthen their memory capabilities even when it comes to senseless contents.

\section{RESULTS}

The starting hypothesis is that students will efficiently memorize the material because the experimental SRI program trains them to separate the relevant from the irrelevant. This coincides with the research where students by asking and answering questions had better memory effects (Bugg \& McDaniel, 2012). The results shown in Table 1 in our research undoubtedly confirm the fact.

By working in experimental conditions both groups achieved a better percentage of facts adoption ( $M$ in Table 1) than in the traditional teaching concept, provided that in b-rooms these differences were not

TABLE 1

The efficiency of memorizing the material with $E$ and $K$ group rotation.

\begin{tabular}{|c|c|c|c|c|c|c|c|}
\hline \multirow{2}{*}{ Students/Groups } & \multicolumn{3}{|c|}{$\begin{array}{c}\text { Experimental } \\
\text { SRI model }\end{array}$} & \multicolumn{2}{|c|}{$\begin{array}{l}\text { Traditional } \\
\text { teaching }\end{array}$} & \multirow[t]{2}{*}{$t$} & \multirow{2}{*}{$p$} \\
\hline & $N$ & $M$ & $S D$ & $M$ & $S D$ & & \\
\hline Class: $2 \mathrm{a}, 3 \mathrm{a}$ i $4 \mathrm{a}$ & 45 & 79.70 & 15.78 & 67.33 & 17.06 & 7.23 & .000 \\
\hline Class: 2b, 3b, 4b & 40 & 76.52 & 16.41 & 73.57 & 15.68 & 1.05 & .302 \\
\hline All classes: 2a, 2b, 3a, 3b, 4a, 4b & 85 & 78.21 & 16.06 & 70.26 & 16.63 & 4.73 & .000 \\
\hline
\end{tabular}

Legend: $\mathbf{2 a}$ - Second class, a room; $\mathbf{2 b}$ - Second class, b room; $\mathbf{3 a}$ - Third class, a room; $\mathbf{3 b}$ - Third class, b room; $4 \mathrm{a}$ - Fourth class, a room; $4 \mathrm{~b}$ - Fourth class, b room; $N$ - Total number of partcipants; $M$ - Sample mean; $S D$ - Standard deviation; $t$ - Student's t distribution; $p$ - Probability. 
statistically significant. This can be explained with the fact that during the application of the SRI model in b-rooms classification period was near so the students were not able to relax and make the most of the experimental program. This raised the questions whether the Grade Point Average in a-rooms was higher than in b-rooms. In order to check this variable, we measured the school grade point average for both a- and b-rooms. It turned out that there was no significant difference $(t=.29$, which is not statistically significant). When we summarized the results from all six classes, it turned out that the SRI contributed to a higher level of facts adoption ( $t=4,73$, important at the level .001; Table 1) than in the traditional teaching. This is because the SRI model trained the students to memorize the key information, and traditional teaching models train them to be reproductive and where they have to learn the material, non-selective memorizing. The experimental SRI program directed the students to separate the relevant from the irrelevant, to memorize the chosen, to value the material, which is analogous to other researches (McNamara, 2004; Noordman et al., 1992; Rogers, 1969). The entire program was conducted in social interaction, with coeducation and cooperation of the students, which is in accordance with Albert Bandura's theory and the theory of social learning (1969).

The second important aspect of our hypothesis in this research is that during the application of the SRI learning model motivational components will be strengthened and that students will learn even when they are memorizing senseless contents. In order to prove this we chose multivariate analysis of covariance (MANCOVA) which is used for testing the influence of time on the motivational components and memorizing senseless contents (Bryman \& Cramer, 2001). The results are shown in Table 2.

\section{TABLE 2}

The influence of time on motivational components and the commitment of students to memorize senseless contents (MANCOVA).

\begin{tabular}{|c|c|c|c|c|c|c|c|c|c|c|c|}
\hline \multirow{2}{*}{ Variables } & \multicolumn{2}{|c|}{ Time 1} & \multicolumn{2}{|c|}{ Time 2} & \multicolumn{2}{|c|}{ Time 3} & \multirow{2}{*}{$W$} & \multirow[b]{2}{*}{$\lambda$} & & \multirow{2}{*}{$F$} & \multirow{2}{*}{$p$} \\
\hline & $M$ & $S D$ & $M$ & $S D$ & $M$ & $S D$ & & & & & \\
\hline Curiosity & 2.80 & .67 & 3.08 & .78 & 3.21 & .59 & .89 & 10.050 & .007 & 25.80 & .000 \\
\hline Imaginatio & 3.11 & .62 & 3.21 & .72 & 3.30 & .58 & .97 & 2.960 & .251 & 7.51 & .008 \\
\hline & .98 & .59 & 3.15 & .75 & & .51 & & .000 & .000 & 4. & .047 \\
\hline Affirm & 2.96 & .50 & 3.28 & .69 & 3.30 & .49 & .8 & .008 & .008 & 28.75 & .000 \\
\hline & 2.90 & .75 & 3.16 & .77 & 3.25 & .64 & .72 & .000 & .000 & 13.34 & .000 \\
\hline SMMSC & 2.94 & .48 & 3.12 & .66 & 3.24 & .39 & .79 & .000 & .000 & 31.31 & .000 \\
\hline
\end{tabular}

Legend: SMMSC - Motivation to memorize senseless contents; $M$ - Sample mean; $S D$ -

Standard deviation; $W$ - Mauchly's test of sphericity; $\chi^{2}$ - Chi-sqvare test; $F$ - F distri-

bution; $p$ - Probability.

Mauchly's test of sphericity tells us if the error covariance matrix is proportional to the identity matrix after orthogonal normalization (Ibid). Since $\chi^{2}$, which is present in all motivation subtests except imagination $\left(\chi^{2}=2.95 ; p=.251\right)$, was significant, it was necessary to adjust $F$ ratio for each of them. After the adjustment we got more $F$ ratio, which confirmed that the differences between the first (Time 1), the second (Time 2) and the third (Time 3) measurement were important for every motivational component (Table 2; last column). If we compare arithmetic mean from the first to the third measurement we will see that time had a positive influence on all motivational components. We recorded a permanent increase in curiosity, imagination, affirmation, competence and students' motivation to remember senseless contents. Only in the last measurement the arithme- tic mean for challenge $(M=3.11)$ was somewhat lower compared to the second measurement (Time 2; $M=3.15$ ), but it is still higher compared to the first measurement $(M=2.98)$. This proves the values of $F$ ratio, which shows that the motivational components remained consistent even in contrasting conditions.

The changes we have presented in the Table 2 undoubtedly show that during the experimental application of the SRI model key motivational components increased. This increase was not linear only for challenge, but we can say that there was no fall in any motivational component of students during the experimental application of the SRI learning model. If specific learning components have a positive influence we can expect other components to have a positive influence as well (Restle, 1957). In separating the relevant from the irrelevant working memory 
comes in the forefront, and while evaluating more elements relevant for learning, persons simultaneously choose the key ones (Awh, 2012). Our experimental program focused on training students to separate the relevant from the irrelevant, to decide what is important and what is less important on their own.

In the traditional teaching process the teacher separates the relevant from the irrelevant, decides what the students have to learn, i.e. memorize, monitors their work and efforts and in the end evaluates how much material is memorized, i.e. learned, whether it be knowledge, skills or habits. The students have a little saying in what facts to choose, to value them and to memorize them in the way that suits them best. In the experimental program where students within their groups asked and answered questions on their own, there were significant changes in the increase of attention and activity of the students and a higher level of self-consciousness and understating the material (Bugg \& McDaniel, 2012). One of the most important self-generation effects issues is the increase of understanding and metaunderstanding of the material, accompanied by the increase of facts knowledge (King, 1992; Rosenshine, Meister, \& Chapman, 1996). The experimental SRI program trained students to think of questions on their own, to answer them within a small group and to present their answers to the other students in the class. This led to the increase of efficient memorizing of the material (Table 1) and enhancing students' motivation (Table 2). It is especially interesting that the students made a progress in memorizing senseless contents (Time $1, M=2.94$; Time 2, $M=3.12$; Time 3, $M=3.24 ; \chi^{2}=19.77$; Table 2), which proves how important it is to practice their own memory.

The third aspect of the general hypothesis relates to the material evaluation. It stems from the logics that those who think that the material is something important will be more successful at separating the relevant from the irrelevant, those who value it more or find it more interesting in comparison to those who learn non-selectively. For testing this relation we used the IM-test (The Importance of the Material) which through a forced choice measures three value orientations of students in relation to the material: important, interesting and non-selective. Those who learn non-selectively or all at once do not pay much attention to the fact which material is relevant or interesting.

\section{TABLE 3}

The importance which students give to the material and learning.

\begin{tabular}{|c|c|c|c|c|c|c|}
\hline \multirow{2}{*}{ Pair of variables } & \multicolumn{2}{|c|}{ The first paired } & \multicolumn{2}{|c|}{ The second paired } & \multirow[b]{2}{*}{$t$} & \multirow[b]{2}{*}{$p$} \\
\hline & $\mathrm{M}$ & SD & M & SD & & \\
\hline Important (I)-Important (M) & 2.66 & 1.18 & 3.05 & 1.41 & -3.93 & .000 \\
\hline Important $(\mathrm{M})$-Important $(\mathrm{F})$ & 3.05 & 1.48 & 3.57 & 1.09 & -3.14 & .002 \\
\hline Important (I)-Important (F) & 2.66 & 1.18 & 3.57 & 1.09 & -6.74 & .000 \\
\hline Interestingly (I)-Interestingly (M) & .41 & .53 & .45 & .59 & -.65 & .521 \\
\hline Interestingly $(\mathrm{M})-$ Interestingly $(\mathrm{F})$ & .45 & .59 & .47 & .80 & -.28 & .778 \\
\hline Interestingly (I)-Interestingly (F) & .41 & .53 & .47 & .80 & -.69 & .494 \\
\hline Indiscriminate (I)-Indiscriminate (M) & 1.93 & 1.19 & 1.50 & 1.42 & 4.13 & .000 \\
\hline Indiscriminate $(\mathrm{M})-$ Indiscriminate $(\mathrm{F})$ & 1.50 & 1.42 & .96 & .80 & 3.02 & .003 \\
\hline Indiscriminate $(\mathrm{I})-$ Indiscriminate $(\mathrm{F})$ & 1.93 & 1.19 & .96 & .80 & 7.00 & .000 \\
\hline
\end{tabular}

Note: Minus shows that $t$-value is in favor of the second variables.

Legend: $M$ - Sample mean; $S D$ - Standard deviation; $t$ - Student's t distribution; $p$ - Probability.

The results of the experimental application of the SRI model show that students regard what they learn relevant (the first three $t$-values in the Table 3). The results also show that this program has no effect on whether the students will regard the material interesting (the next three variables in the Table 3). It is particu- larly encouraging that the SRI program influences decrease in non-selective learning (the last three variables in Table 3). These data undoubtedly show that the SRI model reduces non-selective learning and has a positive effect on the material evaluation which students learn. If we want the children to learn with 
will, to decide what to do learn and experience school as an institution which meets their needs, then we have to win over the value world of the child, as Carl
Rogers suggests (1969). Our experimental testing of the SRI model shows that it has a positive role in children's evaluation of the material.

TABLE 4

Memorizing facts, the teaching design and the material evaluation (ANOVA).

\begin{tabular}{|c|c|c|c|c|c|c|}
\hline \multirow{2}{*}{ Design } & \multirow{2}{*}{ Orientation } & \multicolumn{3}{|c|}{ Memorization of facts } & \multirow{2}{*}{$F_{(2)}$} & \multirow{2}{*}{$p$} \\
\hline & & $N$ & $M$ & $S D$ & & \\
\hline \multirow{4}{*}{$\begin{array}{l}\text { SRI experimental } \\
\text { model of learning }\end{array}$} & Important & 59 & 79.59 & 13.42 & & \\
\hline & Interestingly & 5 & 60.87 & 30.90 & & \\
\hline & Indiscriminate & 21 & 72.82 & 15.83 & & \\
\hline & Total & 85 & 76.81 & 15.94 & 4.38 & .016 \\
\hline \multirow{4}{*}{ Traditional teaching } & Important & 59 & 73.25 & 16.43 & & \\
\hline & Interestingly & 5 & 58.33 & 16.40 & & \\
\hline & Indiscriminate & 21 & 72.86 & 20.73 & & \\
\hline & Total & 85 & 72.28 & 17.72 & 1.68 & .194 \\
\hline
\end{tabular}

Legend: $N$ - Total number of partcipants; $M$ - Sample mean; $S D$ - Standard deviation;

$F$ - F distribution; $p$ - Probability.

Further, we want to know if there are any differences in memorizing facts between the students who consider the material interesting and important in comparison to those students who learn the whole material or who learn non-selectively. For this type of relationship testing we applied a variance analysis (ANOVA). The results show that with the application of the SRI model the students who regard the material relevant are better at memorizing facts than the students who learn non-selectively $\left(F_{(2)}=4.38 ; p=.016\right.$; Table 4), which is statistically significant at the level .05. Those who regard the material interesting, had the lowest score of memorizing facts $(M=60.87)$. This shows that the material which was part of the experiment was not important for the students, but the way of learning - SRI in comparison to the traditional teaching. In the traditional teaching model there was no record of difference in memorizing facts between those who regard the material interesting, appealing, and those who learn non-selectively $\left(F_{(2)}=1.68 ; p=.194\right.$; Table 4), which is not statistically important. Students who learn non-selectively rely on their cognition (Greene Sommerville, Nystorm, Darley, \& Cohen, 2001). Aside from the fact that we noticed positive emotions on the faces and in the behavior of students, we have no records of their emotions during the realization of the SRI program, hence further research in the field should include the measurement of students' emotions.

\section{DISCUSSION}

This research focuses on experimental testing of the SRI learning model. The results show that the training for separating the relevant from the irrelevant (SRI) results in better memorization of facts, increase in motivation and a higher level of positive material evaluation. When students ask question about the material they are learning on their own that leads to a better concentration of attention, a higher level of activity and understanding of the material (Rosenshine et al., 1996). Aside from that, the effects of combining questioning self-generation and answering these questions result in a better memorization of facts and a higher level of metacognition (Bugg \& Mcdaniel, 2012). Our research confirms the fact that questioning self-generation results in better material memorization, but we have also obtained indicators about significant improvements of motivational learning components such as curiosity, imagination, challenge, affirmation and competency. Also, important results on the application of the SRI model in teaching show a higher level of the evaluation of the material being learned.

In order for the SRI model to succeed, we followed the three stages of its implementation: 1) separating relevant, 2) analyzing the contents and 3) evaluating the material being learned (Mayer, 2002; Rinehart \& Thomas, 1993). Aside from that, all the activities of the students were viewed in interaction (Bugg \& McDaniel, 2012), which undoubtedly had positive 
effects. All this was followed by the measurement of students' motivation and their evaluation of the material. It turned out that not only were the students better at memorizing the material, but the level of motivation for learning increased as well as the evaluation of the material being learned. The present study shows that self-generation and answering questions result in better accomplishments at memorizing the material test, as the research results show in the study of Julie Bugg and Mark McDaniel (2012). All this leads to the conclusion that the SRI model is very useful as a compensation for some weak points in the traditional teaching.

The limitations of this study include several components: the length of the program, lack of measurement of students' emotions and longitudinal assessment. The SRI program was carried out in the period of twelve lessons which involved an experimental inclusion of students in this learning technique. It turned out that this was long enough for the students to master this technique, but we do not know if this would lead to saturation due to a long period of application. During the application of the SRI model the students showed positive emotions, but we did not measure them. Further research in the field should include measurement of students' emotions during the process of mastering the SRI learning model. It would be good if the SRI model was tested in a longitudinal research in order to find out if the students would independently and spontaneously apply separating the relevant from the irrelevant model without the teacher's help.

\section{REFERENCES}

Awh, E. (2012). A common discrete resource for visual working memory and visual search. Paper presented at 2012 annual meeting near Munich, Germany, in July 2012: Visual searchand selective attention (VISSA III). Retrived from http://www.mvss.org.

Bandura, A. (1969). Social-learning theory of identificatory processes. In D. A. Goslin (Ed.), Handbook of socialization theory and research (pp. 213-262). Chicago, IL: Rand McNally.

Bandura, A. (1977). Social learning theory. Englewood Cliffs, NJ: Prentice-Hall.

Bryman, A., \& Cramer, D. (2001). Quantitative data analysis with SPSS release 10 for Windows: A guide for social scientists. New York, NY: Routledge.

Bugg, J. M., \& McDaniel, M. A. (2012). Selective benefits of Question self-generation and answering for remembering expository text.
Jurnal of Educational Psychology, 104(4), 922-931. doi: $10.1037 /$ a0028661

Fry, R. W. (1996). Improve your memory. 3rd ed. New York, NY: Book-Smart Press.

Gilovich, T., Griffin, D., \& Kahneman, D. (2002). Heuristics and Biases: The Psychology of Intuitive Judgment. Cambridge, UK: Cambridge University Press. doi: 10.1017/CBO9780511808098

Greene, J. D., Sommerville, R. B., Nystorm, L. E., Darley, J. M., \& Cohen, J. D. (2001). An fMRI investigation of emotional engagement in moral judgment. Science, 293(5537), 2105-2108. doi: 10.1126/science.1062872; PMid:11557895

Griffin, T. D., Wiley, J., \& Thiede, K. W. (2008). Individual differences, rereading, and selfexplanation: Concurrent processing and cue validity as constrains on metacomprehen-sion accuracy. Memory \& Cognition, 36(1), 93-103. doi: 10.3758/MC.36.1.93

Huffman, L. E., \& Spires, H. A. (1994). Effects of explicit instruction in note taking on sixth graders' lecture comprehension and attitudes toward note taking. Reading Improvement, 11, 7276.

Jelić, V. (2013). Pamínje sadržaja s obzirom na značaj koji ucenici pridaju gradivu [Memory contents due to the importance that students attach to school material]. Unpublished master thesisi, Filozofski fakultet, University of Banja Luka.

Kiewra, K., Dubois, N., Christain, D., McShane, A., Meyerhoffer, M., \& Roskelley, D. (1991). Notetaking functions and techniques. Journal of Educational Psychology, 83(2), 240-245. doi: 10.1037/0022-0663.83.2.240

King, A. (1992). Facilitating elaborative learning through guided student-generated questioning. Educational Psychologist, 27(1), 111-126. doi: 10.1207/s15326985ep2801-8.

Mayer, R. R. (2002). The promise of educational psychology. Vol. 2. Teaching for meaningful learning. Columbus, OH: Merrill/Prentice Hall. doi: 10.1207/S15326985EP3702_5; doi: 10.1037/0022-0663.94.3.486; doi: 10.1207/00461520252828528; doi: 10.1037/0022-0663.94.1.171; doi: 10.1207/ S15326985EP3701_3

McNamara, D. S. (2004). SERT: Self-explanation reading training. Discourse Processes, 38(1), 1-30. doi: 10.1207/s15326950dp3801_1

Myers, D. G. (1989). Psychology. New York: Worth Publishers, Inc.

Noordman, L. G. M., Vonk, W., \& Kempff, H. J. (1992). Causal inferences during the reading of 
expository text. Journal of Memory and Language, 31, 573-590. doi:

$$
\text { 10.1016/0749-596X(92)90029-W }
$$

Restle, F. (1957). Theory of selective learning with probable reinforcements. Psychological Review, 64(3), 182-191. doi: 10.1037/h0042600

Rinehart, S. D., \& Thomas, K. A. (1993).

Summarization ability and text recall by novice studiers. Reading Research and Instruction, 32(4), 24-32. doi: 10.1080/19388079309558130

Rogers, C. R. (1969). Freedom to Learn: A View of What Education Might Become. Columbus, $\mathrm{OH}$ : Charles E. Merrill.

Rosenshine, B., Meister, C., \& Chapman, S. (1996). Teaching students to generate questions: A review of the intervention studies. Review of Educational Research, 66(2), 181-221. doi: 10.3102/00346543066002181

Son, L. K., \& Metcalfe, J. (2000). Metacognitive and control strategies in study.time allocation. Journal of Experimental Psychology Learning, Memory, and Cognition, 26(1), 204-221. doi: 10.1073/02787393.26.1.204.

Suzić, N. (2008). Can we motivate students to memorize senseless contents. In A. Kozlowska, R. Kahn, B. Kožuh, A. Kington, and J. Mažgon (Eds.), The role of theory and research in educational practice (pp. 113-133). Unicersity of North Dakota.

Thiede, K. W., Anderson, M. C. M., \& Therriault, D. (2003). Accuracy of metacognitive monitoring affects learning of texts. Journak of Educational Pschology, 95(1), 66-73. doi: 10.1037/0022-0663.95.1.66

Thiede, K. W., Griffin, T. D., Wiley, J., \& Anderson, M. C. M. (2010). Poor metacomprehension accuracy as a result of inappropriate cue use. Discourse Processes, 47, 331-362. doi: $10.1080 / 01638530902959927$.

Ugazio, G., Lamm, C., \& Singer, T. (2012). The role of emotions for moral judgments depends on the type of emotion and moral scenario. Emotion, 12(3). 579-590. doi: 10.1037/a0024611

Young, L., Camprodon, J., Hauser, M., PascualLeone, A., \& Saxe, R. (2010). Disruption of the right temporo-parietal junction with transcranial magnetic stimulation reduces the role of beliefs in moral judgment. Proceedings of the National Academy of Science, USA of the USA, 107, 67536758. doi: 10.1073/pnas.0914826107; PMid: 20351278; PMCid: PMC2872442.

Zhao, Y. (2009). Cathing up or leading the way: American education in the age of globalization. Alexandria, VA: Association for supervision and curriculum development.

Received: October 3, 2013 Revision received: December 19, 2013 Accepted: December 19, 2013

Correspondence to: Nenad Suzić, PhD

Faculty of Philosophy Bulevar V. Petra Bojovića 1A

78000 Banja Luka

Bosni and Herzegovina

Phone: 0038765538500

E-mail: nenad_szc@yahoo.com 